\title{
A TEMÁtica dA HiSTÓRIA dA ÁFrica E dA CULTURA AFRO-BRASILEIRA EM CURRÍCULOS DE CURSOS DE PEDAGOGIA
}

\author{
THE THEMATICS OF THE AFRICA HISTORY AND THE \\ AFRO-BRAZILIAN CULTURE IN CURRICULUMS OF PEDAGOGY COURSES
}

\begin{abstract}
Ramires Santos Teodoro de Carvalho Mestre em Educação pelo Centro Universitário Moura Lacerda - CUML. Professor na rede Municipal de Jardinópolis-SP. Ribeirão Preto, São Paulo - Brasil. ramirestcarvalho@hotmail.com
\end{abstract}

Alessandra David

Doutora em Educação pela Universidade Estadual Paulista - UNESP. Professora do Programa de Pósgraduação em Educação do Centro Universitário Moura Lacerda. Ribeirão Preto, São Paulo - Brasil. davidalessandra@uol.com.br

\begin{abstract}
Resumo: Este artigo tem como objetivo analisar os Planos de Ensino da disciplina Conteúdos e Metodologias do Ensino de História dos cursos de Pedagogia presenciais de Instituições de Ensino Superior num município do interior paulista, e como os P.E. abordam a temática da cultura Africana e Afro-brasileira em seus currículos, tendo como norte a Lei n. 10.639/03. Percebe-se que essa disciplina deveria oferecer subsídios de reflexão para as práticas educativas dos futuros professores assim, esses teriam capacidade de trabalhar com os alunos a formação para a cidadania em torno das temáticas do respeito à diversidade cultural, à compreensão social e a desigualdade na sociedade brasileira. Verificou-se que as bibliografias básica e complementar dos planos estudados pouco abordam o que ensinar e como ensinar os conceitos, as temáticas e as metodologias fundamentais para o estudo da cultura Africana e Afro-brasileira.
\end{abstract}

Palavras-chave: Ensino de história. Cultura afro-brasileira. Curso de pedagogia.

\begin{abstract}
This article aims to analyze the plans of teaching, the content and the methodology of the History learning of the Pedagogy courses upon classroom attendance of institutions of higher education in a town of the interior of São Paulo state, and how the courses approach the African and Afro-Brazilian topics, based on legislation number 10.639/03. It is known that school subject should allow the reflection to education purposes of the future teachers, thus they could have the capacity to work with the students the shaping to the citizenship around the thematics of the respect to cultural diversity, the social comprehension and the inequality in the Brazilian society. It has been found that basic and complementary bibliography of the studied plans do not approach enough what is to teach and how is to teach the concepts, the thematics and the fundamental methodologies for the study of the African and Afro-Brazilian culture.
\end{abstract}

Keywords: History teaching. Afro-brazilian culture. Pedagogy course.

\section{Para citar - ABNT NBR 6023:2018}

CARVALHO, Ramires Santos Teodoro de; DAVID, Alessandra. A temática da história da África e da cultura afrobrasileira em currículos de cursos de pedagogia. Cadernos de Pós-graduação, São Paulo, v. 19, n. 1, p. 57-72, jan./jun. 2020. Disponível em: https://doi.org/10.5585/cpg.v19n1.14910. 
O presente estudo é um recorte da dissertação intitulada "O ensino de História e a formação do pedagogo: análise de planos de ensino da disciplina Conteúdos e Metodologias do ensino de História", na qual analisamos cinco planos de ensino de Instituições de Ensino Superior presenciais de um município do interior paulista, e como desenvolvem os conceitos fundamentais para o estudo da História, ou seja, o fato histórico, o tempo histórico e o sujeito histórico.

Nosso objetivo com este trabalho é apresentar o resultado da análise de um Plano de Ensino investigado na temática da cultura Africana e Afro-brasileira, ancorados nas exigências legais da Constituição Federal (1988): Art. 215. $\int 1^{\circ}$ e $\int 2^{\circ}$, Art. 216 e no Art. 242. $\int 1^{\circ}$; na Lei de Diretrizes e Bases da Educação (LDB) n. 9.394/96: Art. 26-A e Art. 79-B; no Plano Nacional de Educação (PNE: 2014-2024): Meta 7: 7.25 e Meta 12: 12.5; no Parecer CNE/CP n. 1/2004, que Institui as Diretrizes Curriculares Nacionais para a Educação das Relações Étnico-Raciais e para o Ensino de História e Cultura Afro-brasileira e Africana; na Lei n. 10.639, de 9 de janeiro de 2003, que estabelece as Diretrizes e Bases da Educação Nacional, para incluir no currículo oficial da Rede de Ensino a obrigatoriedade da temática "História e Cultura Afro-brasileira", e dá outras providências; e no Decreto n. 4.886, de 20 de novembro de 2003, que Institui a Política Nacional de Promoção da Igualdade Racial - PNPIR e dá outras providências.

O aspecto metodológico da pesquisa teve caráter qualitativo-descritivo, buscando na análise documental, por intermédio dos “conceitos-chave" de Cellard (2010)로 , e sob a luz da perspectiva histórico-crítica ${ }^{2}$ e da teoria crítica do currículo ${ }^{3}$, analisar planos de ensino da disciplina acima descrita, do curso de Pedagogia, de duas Instituições de Ensino Superior.

O uso de documentos em pesquisas científicas permite compreender a dimensão do tempo em relação às transformações políticas e sociais, características essenciais para investigarmos o plano de ensino disponibilizado pela Instituição nas seguintes categorias: ementa, objetivos da disciplina, bibliografia básica e complementar, prescritas para o ensino da disciplina Conteúdos e Metodologias do ensino de História.

Segundo a historiadora Kátia Abud (2006, p. 28) os currículos e programas escolares são intervenções dos próprios órgãos oficiais no ensino, isto significa que a formação dos alunos está intimamente ligada a interesses superiores, ou seja, "o discurso do poder se pronuncia sobre a educação e define seu sentido, forma, finalidade e conteúdo e estabelece, sobre cada disciplina, o controle da informação a ser transmitida e da formação pretendida". Assim sendo, passamos a entender que ensinar História, é extremamente importante para romper com essa supremacia, pois adquire-se ferramentas necessárias para "o saber-fazer, o saber-fazer-bem, lançar os germes do histórico" (SCHMIDT, 2006, p. 57). 
Russo e Paladino (2016, p. 902) apoiados nas obras de Apple (2009) e Silva (1999a, 1999b) esclarecem que "o currículo representa um conjunto de práticas que propiciam a produção, a circulação e o consumo de significados no espaço social, contribuindo intensamente para a construção de identidades sociais e culturais". Se considerarmos o ato de ensinar História como de suma importância para o processo de construção da cidadania é preciso e necessário que professores compreendam e dominem os conceitos básicos do conhecimento histórico.

Pesquisa realizada pelo Instituto Brasileiro de Geografia e Estatística (IBGE) mostra o resultado do módulo Educação, da Pesquisa Anual por Amostra de Domicílios Contínua de 2018 (PNAD-Contínua), publicado em 19 de junho de 2019, revelou que em 2018 o analfabetismo entre pessoas de 15 anos ou mais de cor branca era de 3,9\%, já entre as pessoas de cor preta ou parda atinge $9,1 \%$. Outro dado relevante foi a proporção de pessoas de 25 anos ou mais de idade que finalizaram a educação básica, definida pela Constituição Federal, ou seja, que concluíram o Ensino Médio; o percentual foi maior entre brancos $(55,8 \%)$ do que entre pretos e pardos $(40,3 \%)$.

A média de anos de estudo realizada em 2018 revelou que das pessoas com 25 anos ou mais de idade, em relação à cor ou raça, 10,3 anos de estudos para as pessoas de cor branca e 8,4 anos para as de cor preta e parda. Um dado assustador foi com relação à Educação de Jovens e Adultos (EJA) para o ensino fundamental, 73,7\% que a frequentavam eram pessoas de cor preta ou parda; sendo que, na EJA do ensino médio, o percentual de pessoas pretas ou pardas abarcava 65,7\%. Também, em 2018, a taxa de escolarização líquida das pessoas de 18 a 24 anos que frequentavam cursos de Ensino Superior, independentemente do curso, entre os estudantes de cor branca eram de $36,1 \%$ e, entre pessoas de cor preta ou parda de $18,3 \%$.

A inclusão da temática História da África e dos Afro-brasileiros nos currículos escolares com a Lei n. 10.639/2003, tem por objetivo superar uma história alicerçada na visão eurocêntrica; e o desafio da disciplina de ensino de História no curso de Pedagogia é de contribuir para reflexão e reconhecimento do processo histórico da nação brasileira. Por isso, a formação inicial do professor exige intenso diálogo e reflexão, pois tem como finalidade o combate às desigualdades raciais, propiciando aos alunos condições de compreender, respeitar e aprender sobre a diversidade cultural humana.

Ensinar História é um processo formativo, uma vez que permite pensar o processo de transformações das experiências da sociedade, que é produto da própria intervenção do homem, possibilitando aos alunos estabelecerem comparações e semelhanças entre os grupos sociais nos diversos tempos e espaços. É um despertar para a consciência crítica e uma "alfabetização cultural". Fonseca (2009) entende que a alfabetização cultural contribui para a formação de cidadãos críticos nos anos iniciais, uma vez que propicia o processo de alfabetização e aprendizagem em História, 
facilitando a leitura e a compreensão do tempo, além do combate à intolerância religiosa, cultural, étnica e racial, no espaço escolar. Assim, podemos afirmar que a alfabetização cultural auxilia os alunos a compreenderem sua identidade pessoal e cultural enquanto agente consciente de valores e expressão.

Isso significa que, para compreender, apreender e desenvolver a História nos anos iniciais é preciso desenvolver a consciência histórica e a memória histórica, "pela necessidade de vínculos a serem estabelecidos entre o passado e o presente, e pelo fato de a memória ser uma fonte inesgotável para o trabalho com o passado e com a história" (OLIVEIRA, 2012, p. 238).

O professor deve se constituir como um profissional, pensador, crítico e cidadão por meio de uma formação que articule saberes e práticas concebidas nos diferentes espaços, ou seja, uma educação como um processo construtivo, aberto, permanente, voltado para uma construção histórica e cultural, proporcionando aos alunos o desenvolvimento pessoal e coletivo.

Conceber um ensino problematizador, inserindo os alunos no campo histórico da cultura Afro-brasileira, faz com que os mesmos compreendam as pluralidades de fatos presentes e passados, permitindo identificar a construção do povo brasileiro. Para compreendermos a relação presente-passado, devem ser observados nos anos iniciais, os conceitos fundamentais que norteiam a construção do saber histórico escolar: o tempo, o fato e o sujeito histórico.

A temática Afro-brasileira dispõe de um conjunto de fontes e recursos para o desenvolvimento do trabalho pedagógico em sala de aula. Segundo Conceição (2010, p. 146-147), ensinar cultura Afro-brasileira nos anos iniciais exige um "trato pedagógico da diversidade das experiências históricas (sociais, culturais e étnicas)" como fontes iconográficas (pinturas, retrato, etc.), contação de história sobre os afro-brasileiros; fontes orais (depoimentos, relatos de vida, etc.), fontes escritas (jornais e revistas), além de memórias relatadas em sala de aula; música, com a seleção de repertório Afro-brasileiro; recursos audiovisuais e a cultura imaterial, formada pelo samba de roda, pela expressão musical, entre outros.

Em razão disso, percebe-se a importância de uma boa formação do pedagogo para que ele possa ter fundamentos teóricos e práticos para ensinar História na educação infantil, e, especialmente nos anos iniciais do ensino fundamental, níveis em que pode atuar, visto que, o ensino de História possibilita ao aluno observar, indagar e questionar o modo como se constrói a sua história, o que desenvolve seu sentido de pertencer a sociedade, ou seja, fatores que possibilitam inferir na realidade vivida, identificando passado e presente nos vários espaços coexistentes.

Para se ensinar História na educação infantil e nos anos iniciais do ensino fundamental é preciso considerar o processo de descoberta, da curiosidade e a necessidade de significado, para 
que o processo de aprendizagem do aluno não se esvazie na memorização de fatos e nomes históricos impossibilitando o próprio reconhecimento como agente do processo da história.

Os estudos e a metodologia utilizada por Chervel (1990, p. 185) nos auxiliaram a compreender a estrutura de uma disciplina e sua exata finalidade, pois para o autor, "o que caracteriza o nível superior, é que ele transmite diretamente o saber. Suas práticas coincidem amplamente com suas finalidades, [não havendo] nenhum hiato entre os objetivos distantes e os conteúdos do ensino".

Por isso, para compreendermos a configuração da disciplina escolar, no caso Conteúdo e Metodologia para o Ensino de História e seu plano de ensino, é necessário um desdobramento sobre um número diversificado de materiais históricos, como livros e artigos científicos, legislação e planos de ensino, bibliografias, diretrizes curriculares, resoluções e pareceres do conselho de educação, dentre outros. (GATTI JUNIOR, 2007).

A pesquisa de Fonseca (2010), com base na pesquisa realizada por Gatti e Barreto (2009), serve como referência para inferirmos que os(as) pedagogos(as) com formação generalista, nos cursos de Pedagogia, recebem uma formação deficitária na parte de conteúdos (o que ensinar) e na metodologia de ensino (como ensinar) e a autora conclui que os saberes das disciplinas específicas dos anos iniciais do ensino Fundamental são distintamente depreciados em relação a formação geral do curso de Pedagogia.

Diante do apontamento feito por Fonseca (2010, p. 402), "no qual os problemas e as experiências do mundo acadêmico e do cotidiano escolar não se desvinculam, não se descolam do contexto histórico, social, econômico e cultural em que se situam", apresentamos a seguir, a análise dos planos de ensino da disciplina de Conteúdos e Metodologias do Ensino de História pertencente a uma Instituição de Ensino Superior.

Os três eixos que estruturam o curso de Pedagogia segundo as DCNs-2006 são: formação básica, formação profissional e formação prática; eles também norteiam o plano de ensino do curso de Pedagogia estudado e apresentado, configurando em: apresentação das ementas, bibliografias básica e complementar.

A fim de preservar as identidades das IES conforme o termo de Autorização de Pesquisa, as Instituições foram identificadas por codinomes alfabéticos. Destacamos ainda que o Ministério da Educação (MEC) com o objetivo de assegurar o direito dos alunos à informação sobre o plano de ensino, quanto a metodologia do processo de ensino-aprendizagem e os critérios de avaliação a que serão submetidos publicado na Portaria Normativa n. 40, 12 de dezembro de 2007, e republicada em 20 de dezembro 2010, as seguintes informações: 
Art. 32. $\int 1^{\circ}$. A instituição deverá afixar em local visível junto à Secretaria de alunos, as condições de oferta do curso, informando especificamente o seguinte: IV- matriz curricular do curso;

$\int 2^{\circ} \mathrm{A}$ instituição manterá em página eletrônica própria, e também na biblioteca, para consulta dos alunos ou interessados, registro oficial devidamente atualizado das informações referidas no $\int 1^{\circ}$, além dos seguintes elementos: I - projeto pedagógico do curso e componentes curriculares, sua duração, requisitos e critérios de avaliação; (BRASIL, 2007, grifo nosso).

Igualmente, o Parecer do CNE/CES n. 236/2009, de 7 de agosto de 2009, dispõe sobre os seguintes termos:

É de competência das IES, guardada a devida observância à legislação vigente, divulgar/publicar, em meios acessíveis à comunidade acadêmica, as normas relativas aos planos de curso, critérios de avaliação, metodologias do processo de ensinoaprendizagem e demais informações [...]. (BRASIL, CNE, 2009, grifo nosso).

Dentro desse contexto, percebe-se a importância do planejamento para a teorização da disciplina, como afirma Gil (2012, p. 34) "decidir acerca dos objetivos a ser alcançados pelos alunos, conteúdo programático adequado para o alcance dos objetivos, estratégias e recursos que vai adotar para facilitar a aprendizagem, critérios de avaliação, etc.", como veremos pela análise desses documentos na Instituição estudada. Para melhor visualização foram expostos em negrito apenas as referências sobre a temática de História da África e Cultura Afro-brasileira por meio dos conceitos-chave analisados: tempo-fato-sujeito histórico.

Iniciamos a apresentação da Instituição de Ensino Superior nomeada pela letra alfabética “A”, que teve o curso de Pedagogia reconhecido em 1995. Com caráter de universidade, essa instituição é mantida por uma mantenedora sem fins lucrativos. Possui 65 unidades espalhadas por todo Estado de São Paulo, com mais de 200 mil alunos matriculados, sendo considerada a maior controladora do ensino superior do Estado. No quadro abaixo apresentamos a constituição da disciplina intitulada Metodologia e Prática de Ensino de História e Geografia que permite visualizar as características gerais da mesma. 
Quadro 1 - Plano de Ensino da Instituição "A"

\begin{tabular}{|c|c|c|}
\hline Instituição & Nomenclatura da disciplina & Ementa \\
\hline "A" & $\begin{array}{c}\text { Metodologia e Prática de } \\
\text { Ensino de História e Geografia }\end{array}$ & $\begin{array}{l}\text { Análise da perspectiva de educação escolar a partir dos anos } \\
\text { iniciais de escolaridade. Integração com a Prática de } \\
\text { Ensino/estágio Supervisionado. Análise das áreas do } \\
\text { conhecimento. Estudo dos conteúdos atitudinais, conceituais e } \\
\text { procedimentais de História e Geografia. Introdução dos } \\
\text { objetivos, métodos, técnicas e recursos didáticos para o ensino } \\
\text { de História e Geografia. Desenvolvimento de habilidades e } \\
\text { aquisição de competências. }\end{array}$ \\
\hline Instituição & Nomenclatura da disciplina & Bibliografia básica \\
\hline "A" & $\begin{array}{c}\text { Metodologia e Prática de } \\
\text { Ensino de História e Geografia }\end{array}$ & $\begin{array}{l}\text { ANTUNES, C. A sala de aula de geografia e história: } \\
\text { inteligências múltiplas, aprendizagem significativa e } \\
\text { competências no dia a dia. 5. ed. São Paulo: Papirus, } 2006 \text {. } \\
\text { NEMI, A. L. L.; MARTIN, J. C. Didática de história: o tempo } \\
\text { vivido: uma outra história? São Paulo: FTD, } 1996 \text {. } \\
\text { PENTEADO, H. D. Metodologia do ensino de história e } \\
\text { geografia. São Paulo: Cortez, 2008. }\end{array}$ \\
\hline Instituição & Nomenclatura da disciplina & Bibliografia complementar \\
\hline "A" & $\begin{array}{c}\text { Metodologia e Prática de } \\
\text { Ensino de História e Geografia }\end{array}$ & $\begin{array}{l}\text { BRASIL, Ministério da Educação e do Desporto. Parâmetros } \\
\text { Curriculares Nacionais para o ensino de História e Geografia: } \\
1^{a} \text { a } 4^{a} \text { séries. Brasília: MEC, } 1997 . \\
\text { HAYDT, R. C. C. Curso de didática geral. São Paulo: Ática, } \\
2001 . \\
\text { KARNAL, L. História na sala de aula: conceitos, práticas e } \\
\text { propostas. São Paulo: Contexto, } 2012 . \\
\text { KOZEL, S.; FILIZOLA, R. Didática da geografia: memórias } \\
\text { da terra: o espaço vivido. São Paulo: FTD, 1996. } \\
\text { MIZUKAMI, M. da G. N. Ensino: as abordagens do } \\
\text { processo. São Paulo: EPU, 1986. } \\
\text { BRASIL, Secretaria de Educação Fundamental. Parâmetros } \\
\text { Curriculares Nacionais: caracterização da área de Geografia. } \\
\text { Brasilia: MEC/SEF, 1997. } \\
\text { CARVALHO, A. “A importância dos mapas e dos atlas”. In: } \\
\text { BRASÍLIA, Ministério da Educação e do Desporto. Secretaria } \\
\text { da Educação a Distância. Cadernos da TV Escola: PCN na } \\
\text { escola. Brasília: MEC/ Secretaria da Educação a Distância, } \\
\text { 1998. pp. 29-42. } \\
\text { ROSA, O. Os caminhos da alfabetização cartográfica. Revista } \\
\text { Espaço \& Geografia, Brasília, v. 13. n. 1, 2010. }\end{array}$ \\
\hline
\end{tabular}

Fonte: Elaboração do autor a partir do plano de ensino cedido pela IES.

No caso especifico da ementa da IES "A" constatamos uma fragilidade nos termos de redação e a falta de objetivo a serem trabalhados pelo(a) professor(a), para a formação dos(as) 
futuro(as) pedagogos(as) que irão lecionar História nos anos iniciais. Segundo Gatti e Nunes (2009), a adequação do texto da ementa torna-se relevante por três razões:

Revelar que o próprio professor conhece e sabe dizer de forma sintética o conjunto de temas a serem abordados para a formação dos futuros educadores;

Comunicar aos alunos os compromissos da disciplina, auxiliando no acompanhamento do currículo. $\mathrm{O}$ acesso dos alunos aos programas de ensino tem viabilizado movimentos discentes mais fundamentados e críticos em relação ao trabalho dos professores;

Ainda que menos diretamente relevante para o bom andamento do currículo, a redação adequada de ementas auxilia pesquisadores a se aproximarem de forma mais rigorosa do trabalho proposto em diferentes projetos pedagógicos. (GATTI; NUNES, 2009, p. 33, grifo nosso).

Analisamos nesta pesquisa, apenas o referencial teórico de História referente ao ensino da cultura Africana e Afro-brasileira, pois em algumas Instituições, o conteúdo de Geografia é trabalhado conjuntamente, na mesma disciplina.

$\mathrm{Na}$ Instituição em análise, a bibliografia sobre ensino de História e cultura Afro-brasileira é composta apenas pelos estudos de: PENTEADO, H. D. Metodologia do ensino de história e geografia e KARNAL, L. História na sala de aula: conceitos, práticas e propostas.

A partir da análise dos conceitos-chave do ensino de História, tempo-fato-sujeito histórico, identificados no plano de ensino, compreendendo a ementa e os referenciais teóricos da bibliografia básica e complementar, percebemos fundamentos paradoxais, visto que o enfoque da ementa vincula-se aos objetivos, métodos, técnicas, competência e habilidade para o ensino de História.

As referências utilizadas para o ensino de História trabalham numa vertente de narrativas históricas, numa construção do conhecimento histórico buscando uma metodologia que aproxima os conteúdos dos alunos com a cultura Africana e Afro-brasileira. Ensinar História nos anos iniciais é o pilar fundamental para o desenvolvimento conceitual da criança a respeito do mundo social, como descrito no Parecer n. 03/2004 (BRASIL, CNE, 2005a, p. 21).

O ensino de História e Cultura Afro-Brasileira e Africana, a educação das relações étnico-
raciais, tal como explicita o presente parecer, se desenvolverão no cotidiano das escolas,
nos diferentes níveis e modalidades de ensino, como conteúdo de disciplinas,
particularmente, Educação Artística, Literatura e História do Brasil, sem prejuízo das
demais, em atividades curriculares ou não, trabalhos em salas de aula, nos laboratórios de
ciências e de informática, na utilização de sala de leitura, biblioteca, brinquedoteca, áreas
de recreação, quadra de esportes e outros ambientes escolares.

Entendemos que pelo antagonismo entre a ementa e as bibliografias básica e complementar (que em sua grande maioria datam antes da Lei n. 10.639/2003) a formação sobre a temática étnico racial está extenuada.

Segundo Oliva (2009, p. 145) a presença da História da África nos currículos escolares é insignificante até meados dos anos 1990, pois os livros didáticos, muito utilizados por professores 
nos anos iniciais, abordavam o continente africano de forma secundarizada, e associada ao tráfico negreiro nos séculos XV e XVI, e Imperialismo e Colonialismo do continente. Esse autor ainda acrescenta que a entrada em vigor da LDB n. 9.394/96 e dos PCNs-1997 sinalizaram para uma aproximação, mesmo que frágil, para o estudo da cultura africana.

As formulações para a formação inicial de pedagogos(as) no ensino de História, segundo Fonseca, (2009) e Bittencourt (2011), visam romper e/ou ultrapassar a história tradicional, linear, cronológica e factual, apresentadas em personagens heroicos e datas cívicas de forma atemporal. E explicitam que o conhecimento histórico deve se preocupar com as experiências e as relações humanas em diferentes tempos e espaços, com as permanências e as transformações num processo das ações do homem na construção da identidade pessoal, social e coletiva para a cidadania. "Assim, o estudo da História desde os primeiros anos de escolaridade é fundamental para que o indivíduo possa se conhecer, conhecer os grupos e perceber a diversidade, possibilitando comparações entre grupos sociedades nos diversos tempos e espaços" (FONSECA, 2009, p. 91).

Essa incoerência de selecionar os conteúdos significativos decorre da necessidade de estar atento às condições de ensino, pensar nos conteúdos escolares para se ensinar História é pensar numa perspectiva de significado para os alunos. Nesse sentido, percebemos que a Instituição "A" pouco explora os conceitos básicos do ensino de História, que são o tempo, o fato e o sujeito histórico, a utilização das novas tecnologias, as práticas interdisciplinares como história ambiental, educação e história patrimonial (valorização do patrimônio histórico nacional), uso didático de documentos, e, principalmente as relações étnico-raciais, conforme a Lei n. 10.639/2003 que altera a LDB 9.394/96 incluindo no currículo oficial da Rede de Ensino, o estudo de história e cultura afro-brasileira e indígena, que não foram contemplados no plano de ensino dessa Instituição.

A Instituição denominada "B”, tem caráter de Faculdade. Pertence a um grupo educacional de Sociedade Anônima (S.A) ${ }^{4}$ que possui fins lucrativos de capital fechado, isto é, a divisão das ações e o levantamento de capital acontece apenas entre os acionistas (sócios). Essa IES tem unidades espalhadas por 10 estados brasileiros, iniciou suas atividades acadêmicas no interior paulista no ano de 2000. A disciplina é oferecida no $4^{\circ}$ semestre do curso de Pedagogia, com uma carga horária total de 40h semanais, e tem a denominação de Fundamentos e Práticas do Ensino de História.

A seguir elencamos nos Quadros, a ementa, os objetivos, a programação, a metodologia, os recursos didáticos, a avaliação, além da bibliografia básica e complementar dispostos no plano de ensino disponibilizado para a pesquisa. 
Quadro 2 - Plano de Ensino da Instituição "B"

\begin{tabular}{|c|c|c|}
\hline Instituição & $\begin{array}{l}\text { Nomenclatura da } \\
\text { disciplina }\end{array}$ & Ementa \\
\hline "B" & $\begin{array}{c}\text { Fundamentos e } \\
\text { Práticas do Ensino de } \\
\text { História }\end{array}$ & $\begin{array}{l}\text { Reflexão sobre os conteúdos, os instrumentos que são utilizados e o modo } \\
\text { como se ensina história na educação infantil e no ensino fundamental. } \\
\text { Discussão do ensino de história no contexto histórico e escolar do Brasil. } \\
\text { Estudo do percurso e as propostas teórico-metodológicas dos Parâmetros } \\
\text { Curriculares Nacionais - PCN. Discussão da importância didática e } \\
\text { pedagógica da pesquisa histórico-documental e crítica para o ensino de } \\
\text { História para as séries iniciais do Ensino Fundamental. }\end{array}$ \\
\hline Instituição & $\begin{array}{l}\text { Nomenclatura da } \\
\text { disciplina }\end{array}$ & Bibliografia básica \\
\hline "B” & $\begin{array}{c}\text { Fundamentos e } \\
\text { Práticas do Ensino de } \\
\text { História }\end{array}$ & $\begin{array}{l}\text { BRASIL. Secretaria de Educação Fundamental. Parâmetros curriculares } \\
\text { nacionais: história e geografia. 3. ed. Vol 5. Brasilia: A Secretaria, } 2001 . \\
\text { KISHIMOTO, T. M. (org.). Jogo, brinquedo, brincadeira e a educação. } 3 . \\
\text { ed. São Paulo: Cortez, 1999. } \\
\text { MINISTÈRIO DA EDUCAÇÃO E CULTURA DO BRASIL. Lei de } \\
\text { diretrizes e bases da educação nacional: organização dos textos: leis, } \\
\text { decretos, portarias ministeriais, resoluções e pareceres normativos do } \\
\text { Conselho Nacional de Educação. Belo Horizonte: Lâncer, } 2002 . \\
\text { CABRINI, C.; et al. Ensino de história: revisão urgente. São Paulo: Educ, } \\
\text { 2000. } \\
\text { LUCKESI, C. C. Avaliação da aprendizagem escolar: estudos e } \\
\text { proposições. 15. ed. São Paulo: Cortez, 2003. } \\
\text { NEMI, A. L. L.; MARTINS, J. C. Didática de história: o tempo vivido: } \\
\text { uma outra história? São Paulo: FTD, 1996. } \\
\text { SÃO PAULO (Estado) Secretaria da Educação. Proposta curricular para } \\
\text { o ensino de história: } 1^{\circ} \text { grau. São Paulo, SE/CENP/FLE, 1992. } \\
\text { SCHIMIDT, M. A.; CAINELLI, M. Ensinar história. 2. ed. São Paulo: } \\
\text { Scipione, 2009. }\end{array}$ \\
\hline Instituição & $\begin{array}{l}\text { Nomenclatura da } \\
\text { disciplina }\end{array}$ & Bibliografia complementar \\
\hline "B” & $\begin{array}{c}\text { Fundamentos e } \\
\text { Práticas do Ensino de } \\
\text { História }\end{array}$ & $\begin{array}{l}\text { ANTUNES, C. Educação: } 40 \text { lições da vida de aula. Curitiba: Positivo, } 2004 . \\
\text { CASTRO, A. D.; CARVALHO, A. M. P. (org.). Ensinar a ensinar. São } \\
\text { Paulo: Pioneira Thomson Learning, } 2002 \text {. } \\
\text { FACHIN, O. Fundamentos de metodologia. São Paulo: Saraiva, } \\
\text { 2006. } \\
\text { FARIA, A. L. G. Ideologia no livro didático. 12. ed. São Paulo: Cortez, } 1996 . \\
\text { FARNDON, J. O tempo: como observar e entender o tempo e suas } \\
\text { mudanças. São Paulo: Ática, } 1995 . \\
\text { LIBÂNEO, J. C. Didática. São Paulo: Cortez, 1994. } 371.3 \text { / L67d - } 1 \text { ex. } \\
\text { MARTINS, J. do P. Didática geral: fundamentos, planejamento, } \\
\text { metodologia, avaliação. 2. ed. São Paulo: Atlas, 1990. } \\
\text { SÃO PAULO (Estado). Secretária da Educação. História. São Paulo: } \\
\text { SE/CENP, 1993.4.3 O cinema no ensino e na produção historiográfica. }\end{array}$ \\
\hline
\end{tabular}

Fonte: Elaboração do autor a partir do plano de ensino cedido pela IES.

Segundo Cellard (2010) reconstruir o documento escrito constitui uma fonte preciosa para todo pesquisador. Por isso ao analisarmos a ementa, os objetivos, e os conteúdos programáticos 
encontramos elementos contidos nos planos como: reflexão sobre os conteúdos, os instrumentos que são utilizados e o modo como se ensina história na educação infantil e no ensino fundamental; compreender as sociedades no passado e no presente, do ponto de vista da população excluída e a importância da História como disciplina escolar para o desvelamento da realidade, conduzindo uma metodologia reflexiva por meio de conteúdos críticos que favoreçam a consolidação da cidadania; relações entre saber histórico acadêmico e saber histórico escolar; tempo, espaço, cultura e representação social; histórias e seus sujeitos históricos; histórias, cultura indígena, afro-brasileira e a educação para as relações étnico-raciais.

Por isso, os princípios da educação étnico-racial para uma consciência política e histórica da diversidade, do fortalecimento de identidades e de direitos e ações educativas de combate ao racismo e a discriminação devem ser princípios e metas como apontadas nas Diretrizes Nacionais:

\footnotetext{
Oferecer uma resposta, inclusive no campo da educação, à demanda da população afrodescendente, no sentido de políticas de ações afirmativas: de reparações, e de reconhecimento e valorização de sua história, cultura e identidade;

Fomentar o direito dos negros se reconhecerem na cultura nacional, expressarem visões de mundo próprias, manifestarem com autonomia, individual e coletiva, seus pensamentos;

O direito a uma educação de qualidade: escolas bem preparadas, professores preparados para conduzir a reeducação das relações entre os diferentes grupos étnicos-raciais. (BRASIL, DCN, 2004, p. 10-11).
}

Nota-se que o intuito desses elementos é de situar o aluno na história, fazendo-o enxergar seu lugar no mundo. A História tem esse sentido, fazer com que os alunos construam uma consciência histórica compreendendo seu cotidiano a partir do reconhecimento das diversas experiências históricas das sociedades. É como explicita o historiador francês Georges Duby (1999, p. 9) "para que escrever a história se não for para ajudar seus contemporâneos a ter confiança em seu futuro e abordar com mais recursos as dificuldades que eles encontram cotidianamente?”. Esta pergunta-resposta nos instiga a perceber que ensinar História é transcender um repertório de datas, nomes, conceitos, etc., como visto nos princípios citados do plano de ensino acima mencionado.

Quanto à bibliografia básica utilizada no plano de ensino da instituição "B elencamos o referencial teórico utilizado somente para o ensino de História, CABRINI, C.; et al. Ensino de história: revisão urgente; NEMI, A. L. L.; MARTINS, J. C. Didática de história: o tempo vivido: uma outra história?; SCHIMIDT, M. A.; CAINELLI, M. Ensinar história. Ao fazer a análise do conjunto dos conceitos-chave percebemos que os referenciais teóricos são pouco explorados, pois apenas uma obra data depois da Lei n. 10.639/2003, que perpassam os conceitos apresentados na ementa, em seu objetivo, e em sua programação. Quanto a bibliografia complementar não foi encontrada referencial teórico que fizesse menção ao ensino de História sobre a temática Afrobrasileira. Essa ausência compromete a formação do licenciado, ao não ser exposto a outros 
materiais e referenciais para sua complementação pedagógica e acadêmica, empobrecendo sua análise crítica do que é ensinar História, como aponta Libâneo (2006, p. 860),

\begin{abstract}
a ausência da teoria pedagógica [compromete uma] análise crítica da educação que se pratica nas instituições de formação e nas instituições escolares. A pedagogia, como ciência da educação auxiliada por diferentes campos do conhecimento, estuda criticamente a educação como práxis social, analisando-a, compreendendo-a, interpretando-a em sua complexidade, propondo outros modos e processos para sua concretização, com vistas à construção de uma sociedade justa e igualitária.
\end{abstract}

Entendemos que ensinar História auxilia os alunos a adquirir ferramentas intelectuais para situar-se e compreender-se como cidadão que é, e que está inserido numa sociedade. Para Gatti Junior (2010) o lugar central da História, é a preparação e a formação para a cidadania em torno das temáticas do respeito a diversidade cultural, compreensão social e da desigualdade de mulheres, crianças, idosos, negros e indígenas, como na sociedade brasileira. Em razão disso, a falta de base teórica compromete toda essa estrutura de formação.

Percebe-se que a formação inicial está muito aquém para capacitar futuros professores para compreenderem e valorizem a cultura africana, "o negro, no particular, é o grande desconhecido. Durante todo o percurso da nossa história, a sua contribuição tem sido negada direta ou veladamente e apenas destacadas as suas qualidades como escravo, produtor de uma riqueza de que não participava" (MOURA, 1990, p. 12).

Portanto, a temática África e Afro-brasileira predomina apenas na bibliografia básica analisada no Plano em questão. Sabemos que é no momento de formação inicial que os licenciados em Pedagogia deverão adquirir ferramentas necessárias para formar alunos sujeitos de sua história e da produção do conhecimento histórico, portanto, um currículo mínimo pode comprometer a possibilidade de se trabalhar o protagonismo transformador da realidade vivida pelos alunos.

Para Nemi, Martins, Escanhuela (2009, p.27), "as aulas de história para crianças dos anos inicias do ensino fundamental têm por base a concepção de vida como busca de transformação constante e possível”. Este é o sentido da História, ou seja, dar uma explicação a sociedade sobre si mesma, visto que a História analisa e reflete sobre as transformações ocorridas durante as sociedades, haja vista que as transformações são parte da história (BORGES, 1993).

A partir da análise apresentada dos planos de ensino, aspiramos contribuir para uma inserção e/ou readequação da disciplina Conteúdos e Metodologias do Ensino de História, sobre a temática da Cultura e História da África e Afro-brasileira, no âmbito acadêmico e social, nos currículos dos cursos de licenciatura em Pedagogia.

Ressaltamos que é fundamental para os futuros profissionais do magistério que irão atuar nos anos iniciais, o desenvolvimento sistemático do que é História e a perspectiva da cultura étnicoracial vinculadas as noções de sociedade, economia, política e cultura, permitindo assim aos alunos 
negros e brancos, diante da miscigenação brasileira se reconhecerem como sujeitos históricos a partir da sua realidade e do universo social que o cerca.

Ademais, torna-se possível pelo ensino de História o reconhecimento dos direitos à cidadania tais como: escola, moradia, alimentação, saúde, segurança, etc. É a partir dessas relações que os alunos construirão um cabedal cultural capaz de fazer uma análise política, social e econômica das sociedades ao longo dos tempos e romper com essa problemática instaurada da identidade nacional, uma história oficial da Nação imaginada e pensada num parâmetro da homogeneidade étnico-racial e na da diversidade (CONCEIÇÃO, 2001, p. 25).

Por isso, o conhecimento histórico nada mais é que a relação e a transformação social provocada na natureza, essa concepção metodológica nasce da atividade político-social que concebe a História como uma construção da atividade humana. Acreditamos que o ensino de História possibilita a construção da identidade crítica do sujeito, para que atuando na sociedade em que vive, seja capaz de fazer a relação passado e presente, percebendo-se, sobretudo, como protagonista e transformador da realidade vivida, e um currículo mínimo de História sobre a cultura Africana e Afro-brasileira pode comprometer essa possibilidade.

\section{Referências}

ABUD, Kátia. Currículos de História e políticas públicas: os programas de história do Brasil na escola secundária. In: BITTENCOURT, Circe. (org.). O saber histórico na sala de aula. São Paulo: Contexto, 2006. p. 28-41.

APPLE, Apple, Michael W. A política do conhecimento oficial: faz sentido a ideia de um currículo nacional? In: Moreira, A. F. B.; Silva, Tomaz Tadeu da (orgs.). Currículo, cultura e sociedade. 11. ed. São Paulo: Cortez, 2009. p. 59-91.

BITTENCOURT, Circe Maria Fernandes. Ensino de história: fundamentos e métodos. 4. ed. São Paulo: Cortez, 2011.

BRASIL, Parecer do CNE, n. 236/2009 de 7 de agosto de 2009. Consulta acerca do direito dos alunos à informação sobre o plano de ensino e sobre a metodologia do processo de ensinoaprendizagem e os critérios de avaliação a que serão submetidos. Diário Oficial da União, seção 1, p. 26, 17 de setembro de 2009 .

BRASIL, Portaria Normativa $n^{\circ}$ 40, de 12 de dezembro de 2007. Institui o e-MEC, sistema eletrônico de fluxo de trabalho e gerenciamento de informações relativas aos processos de regulação da educação superior no sistema federal de educação. Diário Oficial da União, seção 1, p. 39-43, 13 de dezembro de 2007.

BRASIL, Conselho Nacional de Educação (2006a). "Resolução CNE/CP n. 1/2006", de 15/5/2006. Diário da União, de 16/5/2006, Seção 1, p. 11. (Disponível em: http://portal.mec.gov.br/cne/arquivos/pdf/rcp01_06.pdf). 
BRASIL, Ministério da Educação. Diretrizes Curriculares Nacionais para a Educação das Relações ÉtnicoRaciais e para o Ensino de História e Cultura Afro-Brasileira e Africana. Brasília: Ministério da Cultura, 2004.

BRASIL, Conselho Nacional de Educação. Parecer CNE/CP 03/2004. Diretrizes Curriculares Nacionais para a Educação das Relações Étnico-Raciais e para o Ensino de História Afro-Brasileira e Africana. Brasília: Ministério da Cultura, 2005.

BRASIL, Decreto no 4.886, de 20 de novembro de 2003. Institui a Política Nacional de Promoção da Igualdade Racial - PNPIR e dá outras providências. Diário Oficial da União, Brasília, 21 nov. 2003.

BRASIL, Lei n. 10.639, de 9 de janeiro de 2003. Diário Oficial da União. 19 de maio de 2004.

BRASIL, Secretaria de Educação Fundamental. Parâmetros Curriculares Nacionais: introdução aos parâmetros curriculares nacionais / Secretaria de Educação Fundamental. Brasília: MEC/SEF, 1997.

BRASIL, Lei de Diretrizes e Bases para a Educação, n. 9.394/96. 3. ed. Brasília: Senado Federal: Subsecretaria de Edições Técnicas, 2006.

BRASIL, Constituição (1988). Constituição da República Federativa do Brasil. Brasília, DF: Senado Federal, 1988.

BRASIL. IBGE-PNAD Contínua 2018: educação avança no país, mas desigualdades raciais e por região persistem. Disponível em:

http://biblioteca.ibge.gov.br/visualizacao/livros/liv101657_informativo.pdf.

CELLARD, André. A análise documental. In: POUPART, Jean.; DESLAURIES, Jean-Pierre.; GROULX, Lional-H.; et al. (orgs.). A pesquisa qualitativa: enfoques epistemológicos e metodológicos. 2. ed. Petrópolis: Vozes, 2010, p. 295-315.

CHERVEL, André. História das Disciplinas Escolares: reflexões sobre um campo de pesquisa. Teoria \& Educação. n. 2, 1990, p. 177-229.

CHERRI, Carlos Rodrigo Monteiro. A mercantilização da educação superior privada: estudo da modalidade de educação a distância na cidade de Ribeirão Preto. Dissertação (Mestrado) - Centro Universitário Moura Lacerda, Ribeirão Preto-SP. 2016.

CONCEIÇÃO, Maria Telvira da. O trabalho em sala de aula com a história e a cultura afrobrasileira no ensino da história. In: OLIVEIRA, Margarida Maria Dias de (org.). História: no ensino fundamental. Brasília: Ministério da Educação, Secretaria de Educação Básica, 2010. p. 131-158.

CONCEIÇÃO, Maria Telvira da. O negro no ensino de história: uma análise das implicações e desafios no contexto do ensino médio. 2001. Dissertação. (Mestrado em Educação). Universidade Federal do Ceará, Fortaleza-CE 2001.

FONSECA, Selva Guimarães. O trabalho do professor na sala de aula: relações entre sujeitos, saberes e práticas. Revista Brasileira de Estudos Pedagógicos, Brasília, v. 91, n. 228, p. 390-407, maio/ago. 2010. 
FONSECA, Selva Guimarães. É possível alfabetizar sem "História"? Ou... Como ensinar História alfabetizando?. In: FONSECA, Selva Guimarães (org.). Ensino Fundamental: conteúdos, métodos e práticas. Campinas, SP: Editora Alínea, 2009. p. 241-265.

GATTI JUNIOR, Décio. A História das Disciplinas Escolares no Brasil: análise dos aspectos teórico-metodológicos e da historiografia educacional. In: IV Congresso de Pesquisa e Ensino em História da Educação em Minas Gerais, 2007, Juiz de Fora. Anais: IV Congresso de Pesquisa e Ensino em História da Educação em Minas Gerais. Juiz de Fora/MG: Editora da Universidade Federal de Juiz de Fora, 2007. p. 1-15.

GATTI, Bernardete Angelina; NUNES, Marina Muniz Rossa (orgs.). Formação de professores para o ensino fundamental: estudo de currículos das licenciaturas em pedagogia, língua portuguesa, matemática e ciências biológicas. São Paulo: FCC/DPE, 2009.

GIL, Antônio Carlos. Metodologia do ensino superior. 4.ed. São Paulo: Atlas, 2012.

OLIVA, Anderson Ribeiro. A história africana nas escolas brasileiras: entre o prescrito e o vivido, da legislação educacional aos olhares dos especialistas (1995-2006). História, Franca, v. 28, n. 2, p. 143-172, 2009.

OLIVEIRA, Sandra Regina Ferreira. O ensino de história para crianças e a formação do professor para os anos iniciais do ensino fundamental. Educativa, Goiânia, v. 15, n. 2, p. 227-241, jul./dez. 2012.

RUSSO, Kelly; PALADINO, Mariana. A lei n. 11.645 e a visão dos professores do Rio de Janeiro sobre a temática indígena na escola. Rev. Bras. Educ., Rio de Janeiro, v. 21, n. 67, p. 897-921, 2016.

SAVIANI, Dermeval A Pedagogia no Brasil: história e teoria. 2. ed. Campinas, São Paulo: Autores Associados, 2012.

SCHMIDT, Maria Auxiliadora. A formação do professor de história e o cotidiano da sala de aula. In: BITTENCOURT, Circe. (org.). O saber histórico na sala de aula. 6. ed. São Paulo: Contexto, 2006. p. 54-66.

SILVA, Tomaz Tadeu da. Documentos de identidade: uma introdução às teorias do currículo. Belo Horizonte: Autêntica, 1999a.

SILVA, Tomaz Tadeu da. O currículo como fetiche. Autêntica: Belo Horizonte, 1999b.

SOUZA, Daniela dos Santos; CRUZ, Gisele Thiel Della. Fundamentos Teóricos e Práticos do Ensino de História. Curitiba: IESDE Brasil, 2009.

\section{Notas}

${ }^{1}$ Os conceitos-chave são a compreensão dos termos empregados por autores nos documentos: "lógica interna, o esquema ou o plano do texto [...]. Essa contextualização pode ser, efetivamente um precioso apoio, quando, por exemplo, comparam-se vários documentos da mesma natureza" (CELLARD, 2010, p. 303).

${ }^{2}$ Dermeval Saviani em seu livro “A Pedagogia no Brasil: história e cultura”, 2012, define a pedagogia histórico-crítica, como uma concepção materialista histórico-dialético, fundamentada na teórica de aspectos filosóficos, históricos, econômicos, e político-sociais 
${ }^{3}$ Segundo SILVA na obra "Documentos de identidade: uma introdução às teorias do currículo", 1999, a teoria crítica do currículo enfatiza os conceitos de: "ideologia, reprodução cultural e social, poder, classe social, capitalismo, relações sociais de produção, conscientização, emancipação e libertação, currículo oculto, resistência”.

${ }^{4}$ As Sociedade Anônimas instituídas pela Lei n. 6.404, de 15 de dezembro de 1976, no qual versão suas características e natureza, art. $1^{\circ}$ A companhia ou sociedade anônima terá o capital dividido em ações, e a responsabilidade dos sócios ou acionistas será limitada ao preço de emissão das ações subscritas ou adquiridas. Ver: CHERRI, Carlos Rodrigo Monteiro. A mercantilização da educação superior privada: estudo da modalidade de educação a distância na cidade de Ribeirão Preto. Dissertação (Mestrado) - Centro Universitário Moura Lacerda, Ribeirão Preto, SP. 2016 